\title{
Prognostic value of late gadolinium enhanced MRI in patients underwent coronary artery bypass graft surgery; long term follow up data
}

\author{
Seung-Ah Lee ${ }^{1 *}$, Yeonyee E Yoon', Jung-Eun Kim', Jin Joo Park, II-Young Oh', Chang-Hwan Yoon', \\ Jung-Won Suh', Jun Sung Kim², Eun Ju Chun ${ }^{3}$, Sang $\|$ Choi $^{3}$, Young-Suk Cho ${ }^{1}$, Tae-Jin Youn ${ }^{1}$, Cheong Lim², \\ Goo-Young Cho', In-Ho Chae ${ }^{1}$, Kay-Hyun Park², Dong-Ju Choi ${ }^{1}$
}

From 18th Annual SCMR Scientific Sessions

Nice, France. 4-7 February 2015

\section{Background}

It has not been well evaluated whether late gadolinium enhanced (LGE)-MRI can provide prognostic information in patients who underwent coronary artery bypass graft (CABG) surgery, especially in patients with preserved left ventricular ejection fraction (LVEF). Further, long-term follow-up data after MRI and CABG surgery are not available. The purpose of this study was to evaluate the impact of myocardial viability assessment by LGE-MRI on prognosis in patients who underwent CABG surgery.

\section{Methods}

A total 145 consecutive patients (age $64.1 \pm 8.8$ years; male $28 \%$ ) with who underwent cine- and LGE-MRI before CABG surgery were investigated. The presence and transmurality (0, absent; $1,1-25 \% ; 2,26-50 \% ; 3$, 51-75\%; 4, 76-100\%) of LGE was visually determined using a standard 17-segment AHA model. LGE score was defined as the sum of each segment scale. The outcome measures were adverse cardiac events (cardiac death, nonfatal myocardial infarction [MI], heart failure $[\mathrm{HF}]$ and unstable angina) and cardiovascular events (adverse cardiac events and stroke).

\section{Results}

LGE was observed in 93 of 145 patients (64.1\%). Average number of segments with LGE was $3.3 \pm 3.6$, and LGE score was $7.8 \pm 9.1$ in the entire study cohort.

${ }^{1}$ Cardiology, Cardiovascular Center, Seoul National University Bundang Hospital, Seongnam-si, Korea (the Republic of)

Full list of author information is available at the end of the article
During a median follow-up period of 8.7 year (Interquartile range, 7.4 to 9.5 years), 47 patients (32.4\%) experienced adverse cardiovascular events (10 cardiovascular deaths, 9 MIs, 9 HFs, 18 unstable anginas and 8 vascular events). The analysis was carried out by strata according to LGE score (LGE score $=0[\mathrm{n}=52] ; 1-11$ $[n=46] ; 12-44[n=47])$. For both adverse cardiac and cardiovascular events, high LGE score of 12-44 were significantly associated with worse event-free survival compared to those without LGE and those with LGE score of $1-11$, in a subgroup with preserved LVEF $\geq 50 \%$. In contrast, high LGE score was not associated with adverse cardiac and cardiovascular events in a subgroup with decreased LVEF $<50 \%$. (Figure 1).

\section{Conclusions}

Myocardial viability assessment by LGE-MRI has impact on prognosis after CABG surgery in patients with preserved LVEF. This observation may extend the indication of viability assessment to those without severe $\mathrm{LV}$ dysfunction before CABG surgery.

\section{Funding}

N/A.

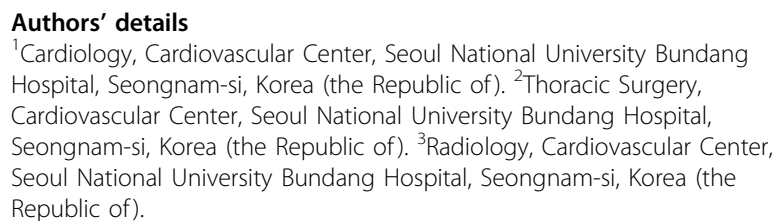
Republic of) 


\section{Adverse cardiac events}

A. $\mathrm{EF}<50 \%$

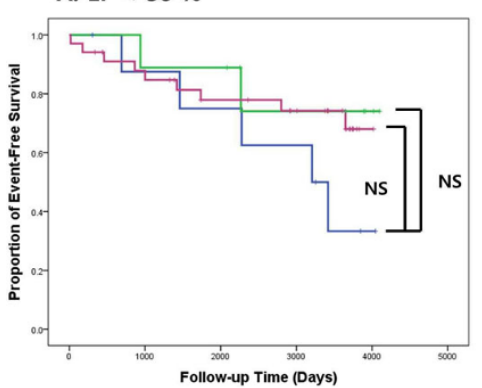

Adverse cardiovascular events

C. $\mathrm{EF}<50 \%$

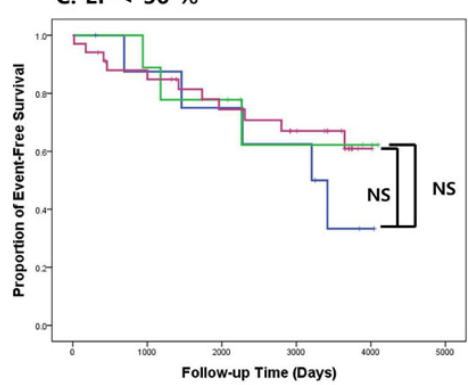

B. $E F \geq 50 \%$

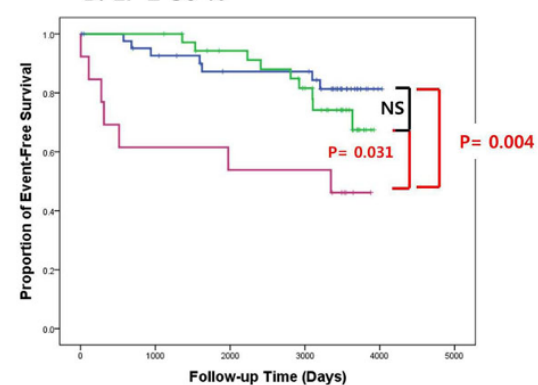

D. $E F \geq 50 \%$

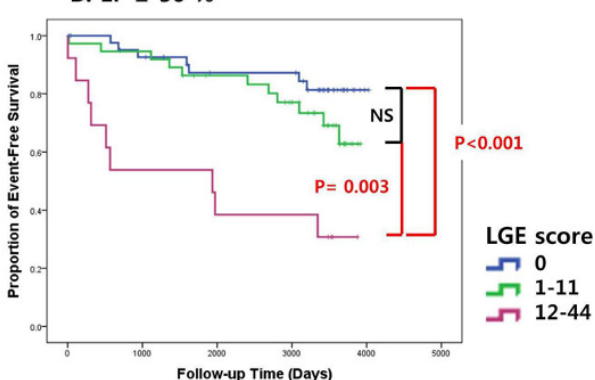

Figure 1 Kaplan-Meier event-free survival curves stratified by LGE score.

Published: 3 February 2015

doi:10.1186/1532-429X-17-S1-P109

Cite this article as: Lee et al:: Prognostic value of late gadolinium

enhanced MRI in patients underwent coronary artery bypass graft

surgery; long term follow up data. Journal of Cardiovascular Magnetic

Resonance 2015 17(Suppl 1):P109.

Submit your next manuscript to BioMed Central and take full advantage of:

- Convenient online submission

- Thorough peer review

- No space constraints or color figure charges

- Immediate publication on acceptance

- Inclusion in PubMed, CAS, Scopus and Google Scholar

- Research which is freely available for redistribution

Submit your manuscript at www.biomedcentral.com/submit 